\title{
AMINAS BIOATIVAS, AMINOÁCIDOS LIVRES E AMÔNIA COMO ÍNDICES DE QUALIDADE DE LEITES FERMENTADOS
}

\section{Bioactive amines, free amino acids and ammonia as quality indexes of fermented milk}

\author{
Naiara Meireles Ciríacol, Gisela de Magalhães Machado Moreira ${ }^{1,2}$, Guilherme Coelho \\ Lopes dos Reis ${ }^{1,3}$, Valterney Lima Deus ${ }^{1}$, Maria Beatriz Abreu Glória ${ }^{1 *}$
}

\begin{abstract}
RESUMO
Leites fermentados são alimentos saudáveis por serem veiculadores de microrganismos probióticos. O objetivo deste estudo foi investigar o perfil e teores de aminoácidos, aminas bioativas e amônia em cinco marcas distintas de leites fermentados antes e após a validade. Dentro da validade, as amostras apresentaram $\mathrm{pH}$ de 4,04 a 4,06, acidez titulável de 0,82 a 0,99 g ácido lático/100 g, sólidos totais de 7,33 a12,0 g/100 g, e teores de espermina de 0,28 a 0,80 mg/kg. Três a 11 aminoácidos livres foram encontrados, dependendo da marca, em teores totais de 4,19 a $17,77 \mathrm{mg} / \mathrm{kg}$. Arginina e asparagina estavam presentes em todas as marcas, enquanto ácido aspártico, leucina e lisina estavam presentes em apenas uma marca cada. Fenilalanina estava presente em duas marcas. Arginina, asparagina, histidina, prolina e treonina foram os aminoácidos predominantes. Após a validade, não houve alteração no $\mathrm{pH}$, acidez e sólidos totais para todas as marcas. O perfil e teores de aminoácidos, aminas e amônia mudaram para três marcas. Novos aminoácidos (glicina e serina) e a amônia foram detectados. Em geral, os teores de prolina, leucina, lisina e fenilalanina aumentaram; enquanto os de asparagina, histidina e treonina diminuíram. Novas aminas foram detectadas: serotonina e agmatina. Análise multivariada (PCA e HCA) confirmou que os aminoácidos glicina e serina e as aminas serotonina e agmatina são potenciais diferenciadores da qualidade de três das cinco marcas pesquisadas de leites fermentados.
\end{abstract}

Palavras-chave: Lactobacillus, arginina, prolina, espermina, aminas biogênicas.

1 Universidade Federal de Minas Gerais, Faculdade de Farmácia, Av. Presidente Antônio Carlos, 6.627, Pampulha, 31270-901, Belo Horizonte, MG, Brasil. E-mail: mbeatriz@ufmg.br

2 Empresa de Pesquisa Agropecuária de Minas Gerais, Instituto de Laticínios Cândido Tostes, Juiz de Fora, MG, Brasil.

3 Universidade Estadual de Campinas, Faculdade de Engenharia de Alimentos, Campinas, SP, Brasil.

* Autor para correspondência

Recebido / Received: 17/01/2019

Aprovado / Approved: 18/03/2019 


\begin{abstract}
Fermented milk is considered a healthy food because it carries probiotic microorganisms. The objective of this study was to investigate the profile and levels of free amino acids, amines and ammonia in five different brands of fermented milk before and after the expiration date. Within shelf life, the samples had $\mathrm{pH}$ of 4.044.06 , titratable acidity of $0.82-0.99 \mathrm{~g}$ lactic acid/100 g, total solids of 7.33-12.0 $\mathrm{g} / 100 \mathrm{~g}$, and spermine levels of $0.28-0.80 \mathrm{mg} / \mathrm{kg}$. Three to 11 amino acids were found depending on the brand, at total levels of 4.19 to $17.77 \mathrm{mg} / \mathrm{kg}$. Arginine and asparagine were present in every brand, whereas aspartic acid, leucine and lysine were present each in only one brand. Phenylalanine was present in two brands. Arginine, asparagine, histidine, proline and threonine were the predominant amino acids. After the expiration date, there was no change in $\mathrm{pH}$, acidity and total solids for all brands. The profile and levels of amino acids and amines changed for three brands. New amino acids (glycine and serine) and ammonia were detected. Overall, the levels of glycine, serine, proline, leucine, lysine and phenylalanine increased; whereas the levels of asparagine, histidine and threonine decreased. New amines were detected - serotonin and agmatine. Multivariate analysis (PCA and HCA) confirmed that the amino acids glycine and serine and the amines serotonin and agmatine are potential differentiators of the quality of three of the five brands of fermented milk.
\end{abstract}

Keywords: Lactobacillus, arginine, proline, spermine, biogenic amines.

\section{INTRODUÇ̃̃̃O}

Leites fermentados são produtos tradicionais e bem estabelecidos na indústria de laticínios (COSTA et al., 2015). As vendas de leite fermentado no Brasil são da ordem de R\$400 milhões por ano e duas marcas representam $82 \%$ destas vendas. Em volume, essas empresas produzem 100 mil toneladas de leite fermentado por ano (MILKPOINT, 2018).

Os leites fermentados têm sido valorizados por serem nutritivos, saudáveis e apresentarem funções probióticas, visando a manutenção da saúde gastrointestinal. As bactérias ácido lácticas (BAL) são amplamente utilizadas no preparo destes produtos, estas promovem o decréscimo do $\mathrm{pH}$ pela conversão da lactose em ácido lático. Ocorre proteólise gerando peptídeos e aminoácidos livres, ácidos graxos e açúcares simples, todos contribuindo para uma melhor digestibilidade do produto e oferecendo propriedades nutricionais e funcionais (SHIBY; MISHRA, 2013). Os benefícios da fermentação por BAL têm sido amplamente reportados (LIÉVIN-LE MOAL; SERVIN, 2014; DI CERBO et al., 2016). Lactobacilli pode aderir e colonizar a mucosa do trato gastrointestinal, trazendo benefícios na regulação do sistema imune intestinal, estimulando a maturação da mucosa intestinal, desenvolvendo papéis relevantes na nutrição e na resistência a bactérias patogênicas gástricas e entéricas (LIÉVIN-LE MOAL; SERVIN, 2014). Além disto, BAL podem produzir poliaminas as quais são fatores de crescimento, importantes na maturação e regeneração da mucosa intestinal e redução da mutagenicidade no intestino de adultos saudáveis (MATSUMOTO; BENNO, 2004; GLORIA, 2006).

Por outro lado, as BAL podem também produzir aminas biogênicas, incluindo, 
tiramina e histamina (BENKERROUM, 2016), as quais, em concentrações elevadas, podem causar efeitos adversos à saúde humana (EFSA, 2011). A histamina e a tiramina são as aminas mais associadas a intoxicações alimentares, com sintomas que incluem: cefaleia, sudorese, queimação, tontura, edema, urticaria, e diarreia para histamina e enxaqueca e crise hipertensiva para a tiramina (EFSA, 2011; ALVAREZ; MORENOARRIBAS, 2014). Putrescina e cadaverina podem potencializar os efeitos adversos destas aminas (ALVAREZ; MORENO-ARRIBAS, 2014). Além dos efeitos prejudiciais à saúde dos consumidores, podem prejudicar as características sensoriais dos alimentos (GLORIA, 2006).

Os principais fatores que afetam a formação e o acúmulo de aminas nos alimentos são a disponibilidade de aminoácidos, e, portanto, a atividade proteolítica, a presença de bactérias capazes de descarboxilar aminoácidos e condições favoráveis à atividade descarboxilante. Outros fatores que podem contribuir para a formação de aminas biogênicas em produtos lácteos fermentados, incluem a qualidade do leite, o tipo de produto, $\mathrm{pH}$, atividade de água, cultura iniciadora, tempo de fermentação, atividade proteolítica, condições no processamento, temperatura e duração do armazenamento (GALGANO et al., 2012; ALVAREZ; MORENO ARRIBAS, 2014). A produção e armazenamento de leite fermentado podem favorecer a formação de aminas biogênicas por aumentar a atividade proteolítica, que incrementa a liberação de aminoácidos (LINARES et al., 2012).

Estudo recente, realizado com bebidas lácteas fermentadas, indicou que as amostras apresentaram características físico-químicas e microbiológicas satisfatórias, bem como contagens totais de bactérias láticas viáveis superiores ao mínimo estabelecido pela legislação (ANDRADE et al., 2015). Entretanto, como resultado da atividade meta- bólica microbiana, a concentração de aminas pode aumentar durante o armazenamento, podendo servir como um índice de qualidade (LORENCOVÁ et al., 2012). São escassas as informações sobre aminas em leite fermentado. Inclusive, não estão disponíveis parâmetros físico-químicos que possam ser utilizados como índice de qualidade do produto. $\mathrm{O}$ objetivo deste estudo foi investigar o perfil e os teores de aminoácidos livres, aminas bioativas livres e amônia em cinco marcas de leites fermentados mais consumidos no Brasil, durante e após o vencimento da validade. As alterações em alguns parâmetros físicoquímicos também foram investigadas.

\section{MATERIAL E MÉTODOS}

\section{Reagentes e amostras}

Padrões de aminas bioativas e aminoácidos e acetonitrila (grau cromatográfico) foram adquiridos da Sigma/Aldrich Co. (St. Louis, MO, EUA), cloreto de amônio (100\%) foi adquirido da Synth (Diadema, SP, Brasil) e 6 aminoquinolil-N-hidroxisuccinimidil carbamato (AQC) - kit Waters AccQ. Fluor ${ }^{\circledR}$ foi adquirido da Waters (Milford, MA, EUA).

As soluções foram preparadas com água ultrapura obtida de Sistema Milli-Q Plus (Millipore Corp., Milford, MA, EUA). As fases móveis foram filtradas em membrana de 0,22 $\mu \mathrm{m}$ de tamanho do poro (Millipore Corp., Milford, MA, EUA).

Amostras de leite fermentado de cinco marcas (A a E) mais comercializadas no território nacional (3 lotes diferentes de cada marca) foram adquiridas em três locais diferentes no mercado varejista de Belo Horizonte (MG), Brasil. Os leites fermentados foram adquiridos aos 6 a 15 dias de fabricação e foram armazenados a $9 \pm 1{ }^{\circ} \mathrm{C}$ por até 60 dias. Imediatamente após a chegada ao laboratório e em intervalos de 15 dias ao longo 
do armazenamento, amostras foram coletadas e analisadas. As amostras foram agrupadas em dois grupos: na validade (dentro da validade); vencida ou fora da validade ( 5 dias após o vencimento da validade). Estas foram analisadas quanto às características físico-químicas ( $\mathrm{pH}$, acidez e sólidos totais), e teores de aminoácidos e aminas bioativas livres e amonia.

\section{Determinação das características físico- químicas}

$\mathrm{O}$ pH, acidez titulável e sólidos totais foram determinados de acordo com Pereira et al. (2001).

\section{Determinação de aminoácidos, aminas bioativas e amônia}

Os aminoácidos livres, aminas bioativas livres e amonia foram quantificados simultaneamente por cromatografia líquida e detecção no ultravioleta (MOREIRA et al., 2017). Para tal, foram utilizadas amostras liofilizadas (K105 Liotop, São Carlos, SP) após pré-congelamento a $-18{ }^{\circ} \mathrm{C} / 48 \mathrm{~h}$. Os analitos foram extraídos com $7 \mathrm{~mL}$ de ácido clorídrico $1 \mathrm{~mol} / \mathrm{L}$, seguido de agitação em agitador orbital Tecnal ${ }^{\circledR}$ modelo TE-140 (250 rpm por 10 minutos), centrifugação (11.180 $g$ por 10 minutos a $4^{\circ} \mathrm{C}$ ) e filtração em papel de filtro qualitativo. Foram realizadas três extrações sucessivas vertendo os filtrados no mesmo balão volumétrico, sendo adicionado o padrão interno L-norvalina para concentração final in column de 25 pmol antes de se completar o balão volumétrico de $25 \mathrm{~mL}$.

Para derivação, o extrato foi neutralizado com igual volume de $\mathrm{NaOH} 1 \mathrm{~mol} / \mathrm{L} \mathrm{e}$ centrifugado (16.000 $\mathrm{g}$, por 10 minutos a $4{ }^{\circ} \mathrm{C}$ ). A $5 \mu \mathrm{L}$ de extrato neutralizado foram adicionados $35 \mu \mathrm{L}$ de tampão borato AccQ. Fluor $^{\circledR}$ e $10 \mu \mathrm{L}$ de reagente AQC. Após 1 minuto de descanso o extrato foi aquecido a $55^{\circ} \mathrm{C} / 10$ minutos em banho-maria para completar a derivação. As amostras derivadas foram filtradas em filtros de $0,22 \mu \mathrm{m}$ de poro (Whatman ${ }^{\circledR}$, GE Healthcare, Reino Unido) para vial Total Recovery ${ }^{\circledR}$ Waters e, analisadas por cromatografia líquida de ultra eficiência (MOREIRA et al., 2017). Foi usado um sistema Waters Acquity ${ }^{\mathbb{B}}$ Ultra Performance LC (UPLC ${ }^{\circledR}$ ) (Waters, Milford, MA, EUA), com detector ultravioleta sintonizável Acquity ${ }^{\circledR}$ a $249 \mathrm{~nm}$, coluna de fase reversa $\mathrm{BEH} \mathrm{C18}(50 \times 2,1 \mathrm{~mm}$ d.i., 1,7 $\mu \mathrm{m}$, Acquity $\mathrm{UPLC}^{\circledR}$ ), e gradiente de eluição de A - tampão acetato de sódio a $0,1 \mathrm{~mol} / \mathrm{L}$ ajustado para pH 4,80 com ácido acético, e B - acetonitrila. O volume de injeção de amostra foi $2 \mu \mathrm{L}$, a vazão da fase móvel foi de $1 \mathrm{~mL} / \mathrm{min}$. O software Waters Empower 2 foi utilizado para controle do UHPLC e aquisição dos dados. A concentração de aminas e aminoácidos foi calculada por interpolação nas respectivas curvas analíticas $\left(\mathrm{R}^{2} \geq 0,971\right)$ para todos os analitos. Os resultados foram expressos em $\mathrm{mg} / \mathrm{kg}$.

\section{Análise estatística}

O experimento foi conduzido em três repetições (lotes diferentes adquiridos em diferentes estabelecimentos). Os resultados foram sujeitos a testes de adequação dos resíduos a pressupostos de normalidade, independência e homocedasticidade. ANOVA e teste de Tukey foram aplicados aos dados, ao nível de significância de 5\%.

Duas técnicas de análise multivariada foram utilizadas para caracterização dos leites fermentados na validade e após vencimento da validade: análise de componentes principais (PCA) e análise de agrupamento hierárquico (HCA). Para a PCA, pH, acidez titulável, aminas livres (espermina, agmatina e serotonina), aminoácidos livres (ácido aspártico, alanina, arginina, asparagina, fenilalanina, glicina, histidina, isoleucina, 
leucina, lisina, prolina, serina, tirosina, treonina e valina), aminoácidos livres totais, aminas bioativas totais e amônia foram usadas como variáveis ativas para a determinação dos componentes principais, e a variável suplementar (validade ou vencida) foi projetada no plano fatorial. A PCA foi conduzida com padronização das variáveis usando matriz de correlação de Pearson. Para análise de HCA, o dendrograma foi obtido por agrupamento das variáveis (utilizando os mesmos parâmetros da PCA). Todas as análises foram conduzidas utilizando o software Minitab ${ }^{\circledR}$ (versão 2017.17.3.1, State College, PA, EUA).

\section{RESULTADOS E DISCUSSÃO}

\section{Caracterização dos leites fermentados durante a validade}

\section{Características físico-químicas}

Os leites fermentados mais comumente consumidos no Brasil foram produzidos com diferentes espécies de Lactobacillus (L. casei difensis, Lactobacillus, L. fortis,
L. casei, e L. casei Shirota, para as marcas A a E, respectivamente) e apresentaram formulações distintas. Os leites fermentados, durante a validade (Tabela 1), apresentaram valores médios de $\mathrm{pH}$ que variaram de 4,04 a 4,06; de acidez titulável de 0,82 a 0,99 g ácido lático/100 g e de sólidos totais de 7,33 a $12,00 \mathrm{~g} / 100 \mathrm{~g}$. Houve diferença significativa $(\mathrm{p}<0,05)$ entre todas as marcas com relação aos teores de sólidos totais. Esta diferença pode ser devida as diferentes formulações usadas por cada indústria. Inclusive, água foi usada como ingrediente em algumas marcas, entretanto, estas não foram as que apresentaram menores teores de sólidos totais. A acidez na marca $\mathrm{A}$ foi menor que a das demais marcas. Todas as amostras de leite fermentado estavam de acordo com a legislação brasileira (BRASIL, 2007), que limita a acidez titulável a valores de 0,6 a 2,0 $\mathrm{g}$ de ácido lático/100 g.

\section{Teores de aminoácidos livres e amônia}

Os tipos e teores de aminoácidos livres e os teores de amônia encontrados nas diferentes marcas de leite fermentado durante

Tabela 1 - Valores médios ( \pm desvio padrão) de pH, acidez titulável e sólidos totais de diferentes marcas de leite fermentado (na validade e vencido) obtidos no mercado consumidor de Belo Horizonte, MG

\begin{tabular}{|c|c|c|c|c|c|c|}
\hline \multirow[t]{2}{*}{ Marca } & \multicolumn{2}{|c|}{ pH } & \multicolumn{2}{|c|}{$\begin{array}{c}\text { Acidez } \\
\text { (g ácido lático/100 g) }\end{array}$} & \multicolumn{2}{|c|}{$\begin{array}{l}\text { Sólidostotais } \\
\quad(\mathrm{g} / \mathbf{1 0 0} \mathrm{g})\end{array}$} \\
\hline & Validade & Vencido & Validade & Vencido & Validade & Vencido \\
\hline A & $4,06 \pm 0,08^{\mathrm{a}, \mathrm{x}}$ & $4,08 \pm 0,14^{\mathrm{a}, \mathrm{x}}$ & $0,82 \pm 0,09^{\mathrm{b}, \mathrm{x}}$ & $0,90 \pm 0,08^{\mathrm{a}, \mathrm{x}}$ & $12,0 \pm 0,00^{\mathrm{a}, \mathrm{x}}$ & $12,0 \pm 0,00^{\mathrm{a}, \mathrm{x}}$ \\
\hline B & $4,04 \pm 0,02^{\mathrm{a}, \mathrm{x}}$ & $4,23 \pm 0,27^{\mathrm{a}, \mathrm{x}}$ & $0,99 \pm 0,06^{\mathrm{a}, \mathrm{x}}$ & $0,98 \pm 0,14^{\mathrm{a}, \mathrm{x}}$ & $9,37 \pm 0,11^{\mathrm{c}, \mathrm{x}}$ & $9,33 \pm 0,00^{\mathrm{c}, \mathrm{x}}$ \\
\hline $\mathrm{C}$ & $4,04 \pm 0,04^{\mathrm{a}, \mathrm{x}}$ & $4,06 \pm 0,03^{\mathrm{a}, \mathrm{x}}$ & $0,99 \pm 0,10^{\mathrm{a}, \mathrm{x}}$ & $0,96 \pm 0,05^{\mathrm{a}, \mathrm{x}}$ & $7,33 \pm 0,37^{\mathrm{e}, \mathrm{x}}$ & $7,22 \pm 0,17^{\mathrm{e}, \mathrm{x}}$ \\
\hline $\mathrm{D}$ & $4,05 \pm 0,07^{\mathrm{a}, \mathrm{x}}$ & $3,99 \pm 0,08^{\mathrm{a}, \mathrm{x}}$ & $0,90 \pm 0,03^{\mathrm{a}, \mathrm{b}, \mathrm{x}}$ & $0,92 \pm 0,04^{\mathrm{a}, \mathrm{x}}$ & $10,4 \pm 0,7^{\mathrm{b}, \mathrm{x}}$ & $11,00 \pm 0,0^{b, x}$ \\
\hline $\mathrm{E}$ & $4,04 \pm 0,04^{\mathrm{a}, \mathrm{x}}$ & $4,06 \pm 0,02^{\mathrm{a}, \mathrm{x}}$ & $0,99 \pm 0,06^{\mathrm{a}, \mathrm{x}}$ & $0,93 \pm 0,02^{\mathrm{a}, \mathrm{x}}$ & $8,39 \pm 0,25^{\mathrm{d}, \mathrm{x}}$ & $8,33 \pm 0,33^{\mathrm{d}, \mathrm{x}}$ \\
\hline
\end{tabular}

$\mathrm{n}$ (validade $) \geq 9 ; \mathrm{n}($ vencido $\geq 6)$ para cada marca.

Valores médios ( \pm desvio padrão) com letras diferentes $[\mathrm{x}, \mathrm{y}]$ para um mesmo produto, na validade ou vencido e [a-e] para um mesmo analito em diferentes marcas separadamente na validade e vencidos são significativamente diferentes (teste de Tukey, $\mathrm{p} \leq 0,05$ ). 
a validade estão indicados na Tabela 2 . Dentre os 20 aminoácidos pesquisados, apenas 13 foram detectados nos produtos: ácido aspártico, alanina, arginina, asparagina, fenilalanina, histidina, isoleucina, leucina, lisina, prolina, tirosina, treonina e valina. Amônia não foi detectada em nenhuma marca. Não foram encontrados nas amostras os aminoácidos: ácido glutâmico, cistina, glicina, glutamina, metionina, serina e triptofano. Arginina e asparagina foram os únicos aminoácidos presentes em todas as amostras de todas as marcas. A variação dos tipos e teores de aminoácidos livres encontrados pode estar diretamente associada aos microrganismos utilizados na produção dos leites fermentados, pois, várias propriedades tecnológicas importantes, como o metabolismo do açúcar, a atividade proteolítica e a atividade da urease, também representam a diversidade fenotípica dentro da espécie de microrganismo utilizado (LADERO et al., 2012; BAO et al., 2016). Esta é a primeira vez que o perfil e os teores de aminoácidos e de aminas livres e amônia são comparados em leites fermentados.

Os teores totais de aminoácidos nos produtos variaram de 4,19 a $17,77 \mathrm{mg} / \mathrm{kg}$, sendo os maiores teores encontrados nas marcas B e E $(\sim 18 \mathrm{mg} / \mathrm{kg})$, seguidos por A $(\sim 14$ $\mathrm{mg} / \mathrm{kg}$ ), e pelos produtos das marcas C e D $(\sim 4 \mathrm{mg} / \mathrm{kg})$. Ao analisar a contribuição de cada aminoácido aos teores totais, nos produtos das marcas A e B, a treonina foi o aminoácido que mais contribuiu (21-31\%), seguido da histidina (22-27\%) e isoleucina (10-12\%). O restante contribuiu com menos de $10 \%$. Os produtos das marcas C e D apresentaram maior contribuição de arginina para os teores totais $(\sim 45 \%)$, seguidos por prolina $(\sim 37 \%)$ e asparagina $(17 \%)$. Os produtos da marca E tinham vários aminoácidos com similar contribuição aos teores totais, incluindo treonina e histidina $(\sim 21$ a $25 \%)$ e alanina, arginina e leucina contribuindo com $\sim 11 \%$.
A predominância de treonina e histidina nos leites fermentados das marcas A e B pode conferir ao produto o sabor amargo, característico destes aminoácidos livres (BAO et al., 2016). Por outro lado, a predominância de prolina nos leites fermentados $\mathrm{C}$ e D pode conferir o sabor adocicado a estes.

Bao et al. (2016) encontraram 18 aminoácidos em leite fermentado com $L$. casei GBHM-21, ou seja, um maior número de aminoácidos. De acordo com Rao et al. (1982), culturas láticas possuem diferentes atividades proteolíticas. Estas não só são capazes de digerir proteínas, mas também podem sintetizar novas proteínas bacterianas, podendo alterar o perfil de aminoácidos do leite fermentado.

\section{Teores de aminas bioativas livres}

Dentre as dez aminas pesquisadas (Tabela 3 ), apenas espermina estava presente nos produtos de todas as marcas, em baixos teores médios que variaram de 0,28 a 0,80 mg/ $\mathrm{kg}$. Os produtos das marcas A, B e C foram aqueles que apresentaram concentrações mais elevadas ( $\mathrm{p} \leq 0,05)$ de espermina $(0,68$ a 0,80 $\mathrm{mg} / \mathrm{kg}$ ) quando comparado aos produtos das marcas D e E $(0,28-0,29 \mathrm{mg} / \mathrm{kg})$.

São escassos os estudos sobre aminas em leites fermentados. Tiramina, em teores que variaram de 3,2 a $6,2 \mathrm{mg} / \mathrm{kg}$, foi detectada em leite fermentado comercializado na República Tcheca, no final da vida de prateleira (BUŇKOVÁ et al., 2013). Os teores totais de aminas biogênicas em leite fermentado são geralmente inferiores a $30 \mathrm{mg}$ / kg (BUŇKOVÁ et al., 2013). Leite e leites fermentados não são fontes significativas de aminas. Em leite de vaca (GLÓRIA et al., 2011; UBALDO et al., 2015) e iogurte (NOVELLA-RODRIGUEZ et al., 2002), a espermidina e a espermina são as aminas predominantes, no entanto, ainda não está claro se estas têm origem endógena ou se são 


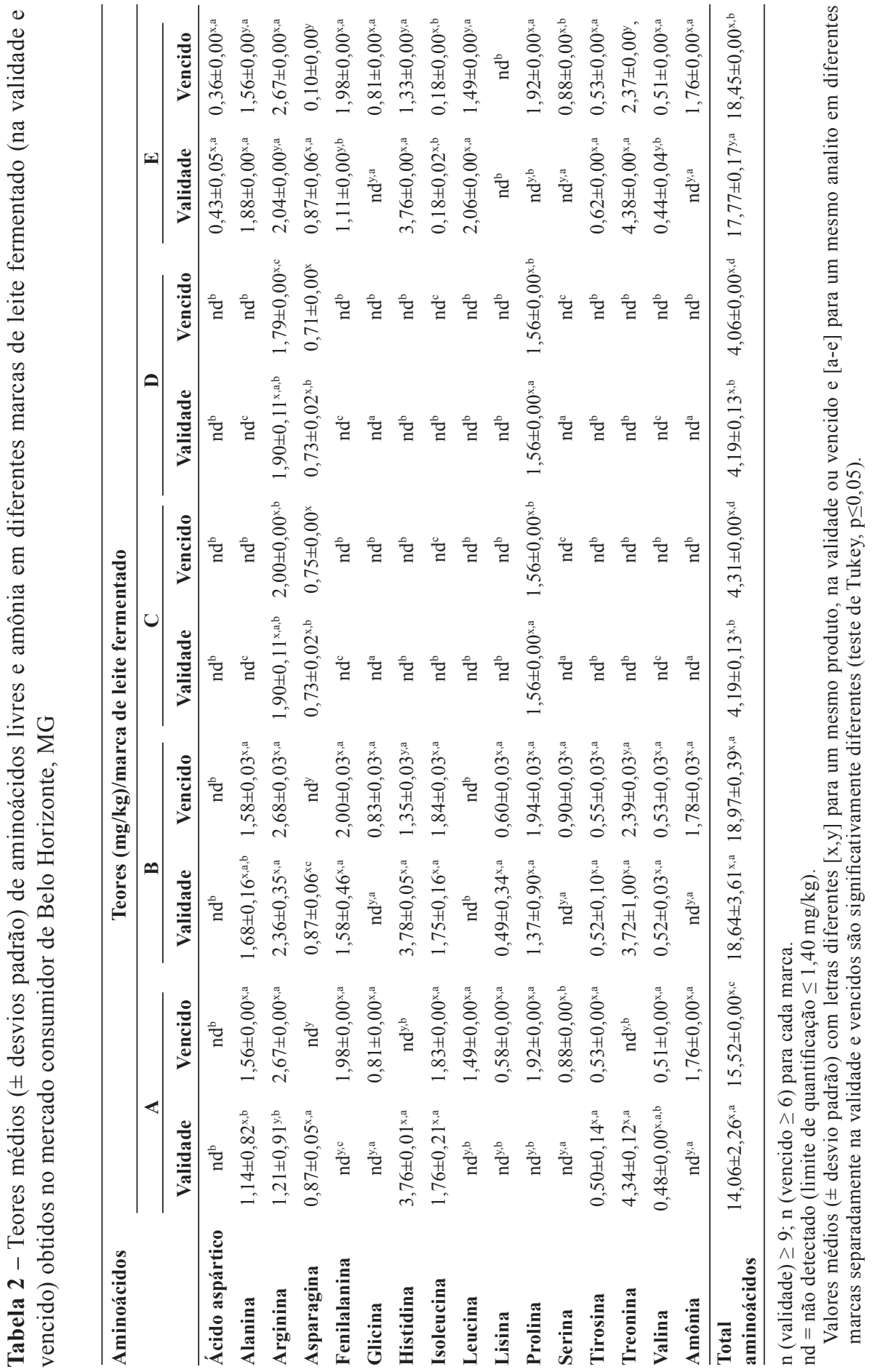


sintetizadas por microrganismos (LINARES et al., 2012). Alguns fatores que afetam as aminas no leite e derivados incluem a carga microbiana e celulas somáticas no leite, a intensidade do tratamento térmico, e o uso de culturas iniciadoras (NOVELLARODRIGUES et al., 2002; UBALDO et al., 2015). As bactérias ácido láticas são descritas como produtoras de histamina, tiramina e putrescina (NOVELLA-RODRIGUES et al., 2002; LADERO et al., 2012) entretanto o tempo de fermentação pode não ter sido longo o suficiente para a formação e acúmulo destas aminas.

A presença de espermina em leite fermentado é relevante, pois esta poliamina tem papel importante na síntese de DNA, RNA e proteínas e na maturação da mucosa intestinal (GLORIA, 2006). Além disso, a espermina tem outras atividades promotoras de saúde, incluindo atividades antioxidante, antinflamatória, e neuroprotetora e inibição da inflamação e antimutagenicidade no trato intestinal (GLORIA, 2006). A presença desta poliamina no leite fermentado pode contribuir para as propriedades funcionais relatadas na introdução.

\section{Caracterização dos leites fermentados após vencimento da validade}

\section{Características físico-químicas}

Após o vencimento da validade dos leites fermentados (Tabela 1), os valores de pH variaram de 3,99 a 4,08; a acidez titulável variou de 0,90 a 0,98 g ácido lático/100 g; e os teores de sólidos solúveis variaram de 7,22 a 12,0 g/100 g. Não houve diferença significativa $(p>0,05)$ nestes parâmetros físico-químicos para amostras na validade e vencidas. Todos os produtos continuavam atendendo a legislação brasileira (BRASIL, 2007), mesmo depois de vencida a validade. Desta forma, nenhum destes parâmetros físico-químicos investigados poderia ser utilizado com um diferenciador de leite fermentado na validade ou vencido.

Tabela 3 - Teores médios ( \pm desvios padrão) de aminas bioativas livres em diferentes marcas de leite fermentado na validade e vencido obtidos no mercado consumidor de Belo Horizonte, MG

\begin{tabular}{ccccccccc}
\hline Marca & \multicolumn{7}{c}{ Teores de aminas (mg/kg) } \\
\cline { 2 - 8 } & \multicolumn{2}{c}{ Espermina } & \multicolumn{2}{c}{ Agmatina } & \multicolumn{2}{c}{ Serotonina } & \multicolumn{2}{c}{ Total } \\
\cline { 2 - 9 } & Validade & Vencido & Validade & Vencido & Validade & Vencido & Validade & Vencido \\
\hline A & $0,68 \pm 0,00^{\mathrm{a}, \mathrm{y}}$ & $0,93 \pm 0,01^{\mathrm{a}, \mathrm{x}}$ & $\mathrm{nd}^{\mathrm{a}, \mathrm{y}}$ & $0,87 \pm 0,00^{\mathrm{a}, \mathrm{x}}$ & $\mathrm{nd} \mathrm{d}^{\mathrm{b}, \mathrm{y}}$ & $0,77 \pm 0,00^{\mathrm{a}, \mathrm{x}}$ & $0,68 \pm 0,00^{\mathrm{a}, \mathrm{y}}$ & $2,57 \pm 0,01^{\mathrm{b}, \mathrm{x}}$ \\
B & $0,80 \pm 0,16^{\mathrm{a}, \mathrm{x}}$ & $0,95 \pm 0,03^{\mathrm{a}, \mathrm{x}}$ & $\mathrm{nd}^{\mathrm{a}, \mathrm{y}}$ & $0,89 \pm 0,03^{\mathrm{a}, \mathrm{x}}$ & $\mathrm{nd} \mathrm{d}^{\mathrm{b}, \mathrm{y}}$ & $0,79 \pm 0,03^{\mathrm{a}, \mathrm{x}}$ & $0,80 \pm 0,16^{\mathrm{a}, \mathrm{y}}$ & $2,63 \pm 0,03^{\mathrm{a}, \mathrm{x}}$ \\
C & $0,67 \pm 0,01^{\mathrm{a}, \mathrm{x}}$ & $0,68 \pm 0,01^{\mathrm{b}, \mathrm{x}}$ & $\mathrm{nd}^{\mathrm{a}, \mathrm{x}}$ & $\mathrm{nd}^{\mathrm{b}, \mathrm{x}}$ & $\mathrm{nd}^{\mathrm{a}, \mathrm{x}}$ & $\mathrm{nd}$ & $0,67 \pm 0,01^{\mathrm{a}, \mathrm{x}}$ & $0,68 \pm 0,01^{\mathrm{d}, \mathrm{x}}$ \\
D & $0,29 \pm 0,02^{\mathrm{b}, \mathrm{x}}$ & $0,31 \pm 0,00^{\mathrm{c}, \mathrm{x}}$ & $\mathrm{nd}^{\mathrm{a}, \mathrm{x}}$ & $\mathrm{nd}^{\mathrm{bx}}$ & $\mathrm{nd}^{\mathrm{a}, \mathrm{x}}$ & $\mathrm{nd}^{\mathrm{b}, \mathrm{x}}$ & $0,29 \pm 0,02^{\mathrm{b}, \mathrm{x}}$ & $0,31 \pm 0,00^{\mathrm{e}, \mathrm{x}}$ \\
E & $0,28 \pm 0,00^{\mathrm{b}, \mathrm{x}}$ & $0,12 \pm 0,00^{\mathrm{d}, \mathrm{x}}$ & $\mathrm{nd}^{\mathrm{a}, \mathrm{y}}$ & $0,87 \pm 0,00^{\mathrm{a}, \mathrm{x}}$ & $\mathrm{nd}^{\mathrm{b}, \mathrm{y}}$ & $0,78 \pm 0,00^{\mathrm{a}, \mathrm{x}}$ & $0,28 \pm 0,00^{\mathrm{b}, \mathrm{y}}$ & $1,77 \pm 0,00^{\mathrm{c}, \mathrm{x}}$ \\
\hline
\end{tabular}

Valores médios ( \pm desvio padrão) com letras diferentes $[\mathrm{x}, \mathrm{y}]$ para um mesmo produto, na validade ou vencido e [a-e] para um mesmo analito e diferentes marcas são significativamente diferentes (teste de Tukey, p $\leq 0,05$ ).

$\mathrm{n}($ validade $) \geq 9 ; \mathrm{n}($ vencido $\geq 6$ ) para cada marca.

nd $=$ não detectado (limite de quantificação $=0,04 \mathrm{mg} / \mathrm{kg}$ ). 


\section{Teores de aminoácidos livres e amônia}

Com relação aos teores de aminoácidos livres (Tabela 2), não houve diferença significativa $(\mathrm{p}>0,05)$ no perfil e teores de aminoácidos para os leites fermentados C e D entre amostras vencidas e na validade. Estes resultados sugerem que não houve atividade proteolítica pelas culturas utilizadas nestes produtos ao longo dos 60 dias de estudo.

Por outro lado, dois aminoácidos não detectados nas amostras dentro da validade foram quantificados nos produtos vencidos das marcas A, B e E - glicina e serina. Houve também mudança no perfil de aminoácidos: na marca $A$, deixaram de ser detectadas a asparagina, histidina e treonina e passaram a ser detectadas fenilalanina, leucina, lisina, prolina, glicina e serina. $\mathrm{Na}$ marca $\mathrm{B}$, a asparagina não foi detectada e passaram a ser detectadas glicina e serina. Na marca E, passaram a ser detectadas prolina, glicina e serina, houve aumento nos teores de arginina e fenilalanina e diminuição nos teores de alanina, asparagina, histidina, leucina e treonina. Assim sendo, para estas três marcas, a presença de glicina e de serina poderia ser indicadora de vencimento da validade.

Houve também variação nos teores de vários aminoácidos quando o produto ultrapassou a validade. Para a marca A, houve aumento significativo $(\mathrm{p}<0,05)$ nos teores de arginina, fenilalanina, glicina, leucina, lisina, prolina e serina; e houve diminuição nos teores de asparagina, histidina e treonina. Para a marca B, houve aumento de glicina e serina e diminuição nos teores de asparagina, histidina, e treonina. Para a marca E, houve decréscimo nos teores de alanina, asparagina, histidina, leucina e treonina e incremento nos teores de arginina, fenilalanina, glicina, isoleucina, prolina, e serina. Apesar das diferenças no perfil e teores de aminoácidos em algumas marcas de leite fermentado vencido comparado aquele dentro da validade, os teores totais de aminoácidos não diferiram entre as amostras das marcas $\mathrm{C}$ e D e também das marcas A, B e E.

Outra diferença entre os leites fermentados durante a validade e vencidos está relacionada à presença de amônia nas amostras vencidas das marcas A, B e E. A presença deste composto indica a existência de atividade proteolítica podendo ser usada como um índice de qualidade.

São escassos os dados na literatura sobre a alteração do perfil de aminoácidos em leites fermentados como os incluídos neste estudo. Entretanto, a diminuição dos teores de treonina e o aumento nos teores de lisina e amônia foram também observados por RAO et al. (1982), que ainda observaram diminuição de metionina, treonina e valina e aumento nos teores de ácido glutâmico e lisina e amônia durante a fermentação por L. acidophilus e L. bulgaricus, sendo que o primeiro produziu leucina e tirosina.

\section{Teores de aminas bioativas livres}

Com o vencimento da validade houve o aparecimento de agmatina e serotonina, não detectadas nas amostras dentro da validade. Isto aconteceu apenas para as marcas A, B e E. A agmatina pode resultar da descarboxilação da arginina, sendo também um precursor na formação das poliaminas via putrescina (GLORIA, 2006; BARBIERI et al., 2019). A serotonina pode ser formada via triptofano ou triptamina (GLORIA, 2006), mas nenhum destes precursores foi encontrado nos leites fermentados durante a validade.

A produção de aminas biogênicas por BAL tem sido descrita na literatura. Estas bactérias podem produzir energia metabólica, utilizando vias catabólicas que convertem os aminoácidos nas aminas, visto que as BAL não possuem a cadeia respiratória como fonte de ATP (GLORIA, 2006; GEZGINC et al., 2013). A descarboxilação de aminoácidos pode também aumentar a sobrevivência das bactérias sob condições de estresse, pelo consumo de prótons e da excreção de aminas 
e $\mathrm{CO}_{2}$, ajudando a restaurar o $\mathrm{pH}$ externo. $\mathrm{O}$ pH de leite fermentado é considerado um fator favorável para a ação de descarboxilases e formação de aminas (LORENCOVÁ et al., 2012). Ainda, tem sido relatada a relação entre um $\mathrm{pH}$ ácido e o aumento na produção de aminas (GEZGINC et al., 2013). Os genes codificadores para a descarboxilação podem ser induzidos em baixos valores de pH (LINARES et al., 2012).

A capacidade das BAL em descarboxilizar aminoácidos é variável, podendo ser relacionada à estirpe, mais do que à especie. Esta é uma característica adquirida por transferência de genes horizontal associada à plasmideo, elementos móveis ou ilhas de resistência à acidez (LINARES et al., 2012).

Assim, a presença de aminas biogênicas (além da poliamina espermina), pode ser um indicador da qualidade de leite fermentado. Ainda, para minimizar a formação de aminas em leite fermentado, a seleção da linhagem das bactérias láticas pode ser realizada modulando o perfil de aminas, entretanto, estas modificações podem causar alterações no sabor ou na textura (GEZGINC et al., 2013).

\section{Análise multivariada dos leites fermentados na validade e vencidos}

Pela análise dos componentes principais (PCA), os dois primeiros componentes representaram $85 \%$ da variância total. Foram evidenciados três grupos dos leites fermentados, sendo que as amostras A, B e E, dentro da validade ficaram no lado esquerdo superior do gráfico (Figura 1B); as amostras A, B e E vencidas (fora da validade) ficaram no lado direito inferior; e as amostras C e D, tanto aquelas na validade quanto as vencidas, ficaram no lado esquerdo inferior do gráfico. PC1 contribuiu com $71 \%$ da variância total (Figura 1A) e correlacionou positivamente $(+0,3)$ com vários aminoácidos (cistina, fenilalanina, glicina, arginina), com a amônia, e com a amina, e negativamente com a arginina $(-0,3)$. PC2 contribuiu com $14 \%$ da variância total e as maiores correlações positivas $(0,5)$ foram observadas para histidina e treonina e a negativa $(-0,4)$ para a prolina. HCA (Figura 1C) das observações confirmou a discriminação em três grupos: (i) A, B e E na validade; (ii) $\mathrm{C}$ e $\mathrm{D}$ tanto na validade quanto vencido); e (iii) A, B e E vencidos. Este arranjo sugere que os leites fermentados $\mathrm{A}$, $B$ e E podem ser diferenciados em função de estarem na validade ou vencidos; mostrando que a amina agmatina e alguns aminoácidos podem contribuir para a diferenciação da validade dos leites fermentados. Por outro lado, os parâmetros investigados não foram capazes de diferenciar os leites fermentados das marcas C e D.

\section{Considerações finais}

De acordo com os resultados obtidos para as análises físico-químicas ( $\mathrm{pH}$ e acidez) não houve diferença significativa para todas as marcas de leite fermentado durante e fora da validade. Ainda, os produtos das marcas $C$ e D não apresentaram variação significativa para todos os parâmetros investigados em função da validade/vencimento. Estes resultados sugerem não ter havido atividade das bactérias nas amostras C e D. De fato, Lactobacillus spp. são susceptíveis a uma serie de estresses ambientais, tais como térmico, acidez, pressão osmótica e oxidação (LIN et al., 2016), o que pode ter interferido na sua atividade. Por outro lado, houve diferença para as amostras A, $\mathrm{B}$ e E, indicando atividade em relação aos aminoácidos: durante a validade, foram elevados os teores dos aminoácidos histidina, treonina e asparagina; por outro lado, após o vencimento, passaram a ser predominantes os aminoácidos glicina, serina, prolina, da amônia e das aminas biogênicas (serotonina e agmatina). Baseado nestes resultados, 


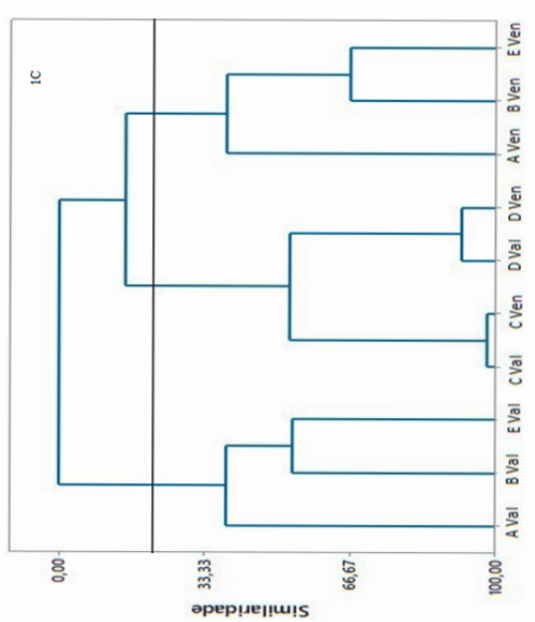

풀

클

วิ

뜤

茄 띠

留

$\varangle$

记

I

0)

$\exists$

들

过

( )

\&

(1)

옹.

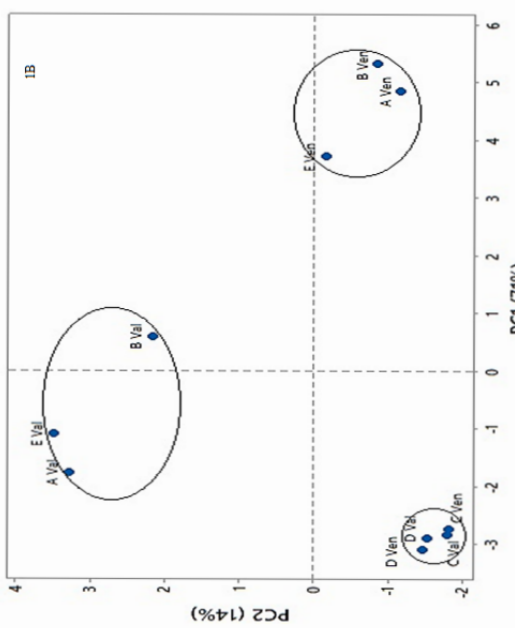

의

윰

\&

o.

,

䒕

กิ $\frac{7}{3}$

政

$\leq \Xi$

ज

퓹. 즘

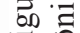

进要

$\varangle$ 宁

نे

$1 \geqq$

䑻

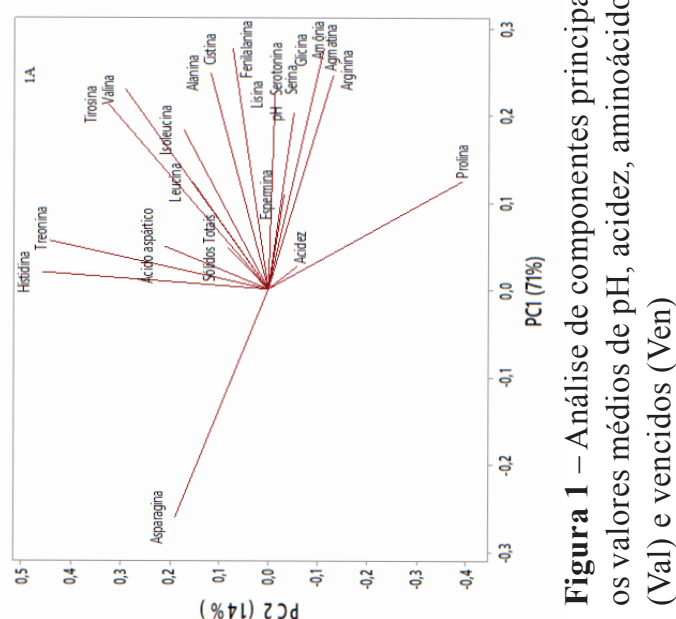


mais estudos são necessários para o estabelecimento de um índice para avaliação da qualidade de leites fermentados.

\section{CONCLUSÃO}

Durante a validade, as cinco diferentes marcas de leite fermentado apresentaram valores similares para algumas características físico-químicas ( $\mathrm{pH}$, acidez titulável e sólidos totais). Foram detectados 3 a 11 aminoácidos livres dependendo da marca, sendo a arginina e asparagina comuns a todas as marcas. Apenas a amina espermina foi encontrada em todas as amostras, em baixos teores $(\leq 0,80 \mathrm{mg} / \mathrm{kg})$.

As diferentes marcas de leite fermentado, após o vencimento da validade, apresentaram similares valores de $\mathrm{pH}$ e acidez, comparado aos dos produtos na validade. Não houve variação nos teores totais e tipos de aminoácidos e aminas e amônia não foi detectada em algumas marcas (C e D). Entretanto, nas demais marcas apareceram os aminoácidos glicina, prolina e serina, a amônia e as aminas, agmatina e serotonina. Houve também redução nos teores de asparagina nestas marcas. Análise multivariada (PCA e HCA) confirmou que os aminoácidos glicina e serina e as aminas serotonina e agmatina são potenciais diferenciadores da qualidade de três das cinco marcas de leites fermentados.

\section{REFERÊNCIAS}

ALVAREZ, M. A.; MORENO-ARRIBAS, M. V. The problem of biogenic amines in fermented foods and the use of potential biogenic amine-degrading microorganisms as a solution. Trends in Food Science \& Technology, v. 39, p 146-155, 2014.

ANDRADE, E. H. P.; SILVA, N. M. A.; RESENDE, M. F. S., SOUZA, M. R.; FONSECA, L. M.; CERQUEIRA, M. M. O. P.; PENNA, C. F. A. M., LEITE, M. O.
Microbiological and physical-chemical characteristics of fermented milk beverages. Arquivos Brasileiro de Medicina Veterinária e Zootecnia, v. 67, n. 6, p. 1735-1742, 2015.

BAO, Z.; XIONG, J.; LIN, W.; YE, J. Profiles of free fatty acids, free amino acids, and volatile compounds of milk bases fermented by Lactobacillus casei GBHM-21 with different fat levels. CyTA Journal of Food, v. 14, n. 1, p. 10-17, 2016.

BARBIERI, F.; MONTANARI, C.; GARDINI, F.; TABANELLI, G. Biogenic amine production by lactic acid bacteria: a review. Foods, v. 8, n. 17, p. 1-27, 2019.

BENKERROUM, N. Biogenic amines in dairy products: origin, incidence, and control means. Comprehensive Reviews in Food Science and Food Safety, v. 15, p. 801-826, 2016.

BRASIL. Ministério da Agricultura e do Abastecimento, Secretaria de Defesa Agropecuária, Departamento de Inspeção de Produtos de Origem Animal. Padrões de identidade e qualidade de leites fermentados. Resolução nº46, de 23/10/2007. Diário Oficial da União, Brasília, 24 out. 2007. Seção I, p. 4.

BUŇKOVÁ, L.; ADAMCOVÁ, G.; HUDCOVÁ, K.; VELIVHOVÁ, H.; PACHLOVÁ, V.; LORENCOVÁ, E.; BUŇKA, F. Monitoring of biogenic amines in cheeses manufactured at small-scale farms and in fermented dairy products in the Czech Republic. Food Chemistry, v. 141, p. 548$551,2013$.

COSTA, M. P.; BALTHAZAR, C. F.; MOREIRA, R. V. B.; CRUZ, A. G.; JUNIOR, C. A. C. Determination of biogenic amines 
by high-performance liquid chromatography (HPLC-DAD) in probiotic cow's and goat's fermented milks and acceptance. Food Science \& Nutrition, v. 3, n. 3, p. 172-178, 2015.

DI CERBO, A.; PALMIERI, B.; APONTE, M.; MORALES-MEDINA, J. C.; IANNITTI, T. Mechanisms and therapeutic effectiveness of lactobacilli. Journal of Clinical Pathology, v. 69, p. $187-203,2016$.

EFSA (European Food Safety Authority). Scientific opinion on risk based control of biogenic amines formation in fermented foods.

EFSA Journal, v. 9, n. 10, p. 2392, 2011.

GALGANO, F.; CARUSO, M.; CONDELLI, N.; FAVATI, F. Focused review: Agmatine in fermented foods. Frontiers in Microbiology, v. 3, n. JUN, p. 1-7, 2012.

GEZGINC, Y.; AKYOL, I.; KULEY, E. Ö. F. Biogenic amines formation in Streptococcus thermophilus isolated from home-made natural yogurt. Food Chemistry, v. 138, n. 1, p. 655-662, 2013.

GLORIA, M. B. A. Bioactive Amines. In: HUI, Y. H. Handbook of Food Science Technology and Engineering. v. 1. Boca Raton: Taylor \& Francis, 2006, p.13-38.

GLÓRIA, M. B. A.; SARAIVA, P. R. L.; RIGUEIRA, J. C. S.; BRANDAO, S. C. C. Bioactive amines changes in raw and sterilized milk inoculated with Pseudomonas fluorescens stored at different temperatures. International Journal of Dairy Technology, v. 64, p. 45-51, 2011.

LADERO, V.; FERNÁNDEZ, M.; CALLESENRÍQUEZ, M.; SÁNCHEZ-LLANA, E.; CAÑEDO, E.; MARTÍN, M. C.; ÁLVAREZ, M. A. Is biogenic amines production a strain- dependent trait in enterococci? Food Microbiology, v. 30, p. 132-138, 2012.

LIÉVIN-LE MOAL, V.; SERVIN, A. L. Antiinfective activities of Lactobacillus strains in the human intestinal microbiota: from probiotics to gastrointestinal anti-infectious biotherapeutic agents. Clinical Microbiology Reviews, v. 27, n. 2, p. 167-199, 2014.

LIN, J.; ZOU, Y.; CAO, K.; MA, C.; Chen, $Z$. The impact of heterologous catalase expression and superoxide dismutase overexpression on enhancing the oxidative resistance in Lactobacillus casei. Journal of Industrial Microbiology and Biotechnology, v. 43, p. 703-711, 2016.

LINARES, D. M.; RÍO, B.; LADERO, V.; MARTÍNEZ, N.; FERNÁNDEZ, M.; MARTÍN, M. C.; ÁlVAREZ, M. A. Factors influencing biogenic amines accumulation in dairy products. Frontiers in Microbiology, v. 3, n. 5, p. 1-10, 2012.

LORENCOVÁ, E.; BUŇKOVÁ, L.; MATOULKOVÁ, D.; DRÁB, V.; PLEVA, P.; KUBÁŇ, V.; BUŇKA, F. Production of biogenic amines by lactic acid bacteria and bifidobacteria isolated from dairy products and beer. International Journal of Food Science and Technology, v. 47, p. 2086-2091, 2012.

MATSUMOTO, M.; BENNO, Y. Consumption of Bifidobacterium lactis LKM512 yogurt reduces gut mutagenicity by increasing gut polyamine contents in healthy adult subjects. Mutation Research, v. 568, p. 147-153, 2004.

MILKPOINT, Mercado global de iogurtes de beber expandirá US\$ 13 bilhões nos próximos quatro anos. PORTAL MILKPOINT. Disponível em: http://www.milkpoint.com. br/industria/cadeia-do-leite/giro-de-noticias/ 
mercado-global-de-iogurtes-de-beberexpandira-us-13-bilhoes-nos-proximosquatro-anos-98857n.aspx 12/2/2016 Acesso em 11 jan. 2018.

MOREIRA, G. M. M.; SOBRAL, D.; COSTA, R. G. B.; PAULA, J. C. J.; FERNANDES, C.; GLÓRIA, M. B. A. Parâmetros de desempenho em método UHPLC-UV para quantificação de aminoácidos livres e aminas bioativas em queijos mussarela, prato, parmesão e gorgonzola. Revista Instituto Laticínios Cândido Tostes, Juiz de Fora, v. 72, n. 4, p. 192-204, 2017.

NOVELLA-RODRIGUES, S.; VECIANANOGUES, M. T.; ROIG-SAGUES, A. X.; TRUJILLO-MESA, A. J.; VIDAL-CAROU, M. C. Influence of stater and nonstarter on the formation of biogenic amine in goat cheese during ripening. Journal of Dairy Science, v. 85, p. 2471-2478, 2002.
PEREIRA, D. B. C.; SILVA, P. H. F.; COSTA JÚNIOR, L. C. G.; OLIVEIRA, L. L. Físico Química do Leite e Derivados: Métodos Analíticos. 2. ed. Juiz de Fora: Templo Gráfica e Editora, 2001.

RAO, D. R.; PULUSANI, S. R.; RAO, T. $\mathrm{K}$. Amino acid composition and nutritional implications of milk fermented by various lactic cultures. Journal of Food Quality, v. 5, p. 235-243, 1982.

SHIBY, V. K.; MISHRA, H. N. Fermented milks and milk products as functional foods - a review. Critical Reviews in Food Science and Nutrition. v. 53, n. 5, p. 482-96, 2013.

UBALDO, J. C. S.; CARVAlHo, A. F.; FONSECA, L. M.; GLÓRIA, M. B. A. Bioactive amines in mozzarella cheese from milk with varying somatic cell counts. Food Chemistry, v. 178, p. 229-235, 2015 